\title{
FATIGUE LIFE CALCULATIONS OF MACHINE COMPONENTS IN APPROACH OF STRESS, STRAIN AND ENERGY
}

\begin{abstract}
B. Ligaj *, K. Karolewska**
Abstract: The paper presents the experimental verification of fatigue life calculation in the conditions of programmable loads. In order to assess of accuracy of the calculations, the experimental research of the C45 steel were carried out under static load condition $(R=-1)$, and under programmable loads. The research was realized under stress control condition. On the basis of obtained results, the fatigue life diagram in approach of stress $\left(S_{a}-N\right)$, strain $\left(\varepsilon_{a c}-2 N_{f}\right)$ and energy were $\left(\Delta W_{p l}-N\right)$. A comparative analysis of calculation results with the results of experimental tests for two step loadings revealed a significant influence of the maximal stress values in the spectrum on fatigue life, for each of the applied calculation methods.
\end{abstract}

Keywords: fatigue life calculations, S-N curve, Palmgren-Miner hypothesis, machine components, $\mathbf{C 4 5}$ steel, 1045 steel

\section{Introduction}

The fatigue life calculations of machinery parts are realized in stress, strain, and energy terms. To assume the appropriate calculation method depends on the load value and the expect range of fatigue life: low cycle fatigue (LCF) or high cycle fatigue (HCF).

Calculation of fatigue life is largely affected by the results of experimental tests in the field of cyclic properties description, according to the stress based approach (Kurek, Lagoda, Katzy, 2014), strain based approach (Szala, Ligaj, 2012) or energy based approach (Ligaj, 2014). The tests are conducted for nonstandard research objects (Szala, Ligaj, 2016) and with the use of original fatigue measuring methods (Wirwicki, Topolinski, 2014). The indicated methods of life calculation can be used when designing machine elements, examples of which are presented in the works: ship elements (Flizikowski, et al., 2017) and elements of cutting assemblies (Zastempowski, Bochat, Wesołowski, 2015).

The aim of the paper is the experimental verification of $\mathrm{C} 45$ steel fatigue life calculations in terms of stress, strain, and energy.

\section{Tests results}

\subsection{Research object}

Tests in static conditions were performed according to PN-EN ISO 6892-1:2010 standard. The mean value of strength parameters of $C 45$ steel is: yield point $R_{e}=S_{y}=458 \mathrm{MPa}(1.4 \mathrm{MPa})$, the material tensile strength $\mathrm{R}_{\mathrm{m}}=\mathrm{S}_{\mathrm{u}}=682 \mathrm{MPa}(7.1 \mathrm{MPa})$, elastic modulus $\mathrm{E}=2.15 \cdot 10^{5} \mathrm{MPa}(7954 \mathrm{MPa})$. In brackets there are values of standard deviation.

Prof. Bogdan Ligaj, PhD.: Faculty of Mechanical Engineering, UTP University of Science and Technology in Bydgoszczy, al. Prof. S. Kaliskiego 7, 85-796 Bydgoszcz, PL, e-mail: bogdan.ligaj@utp.edu.pl

** Assoc. Prof. Karolina Karolewska: Faculty of Mechanical Engineering, UTP University of Science and Technology in Bydgoszczy, al. Prof. S. Kaliskiego 7, 85-796 Bydgoszcz, PL, e-mail: 
Cyclic properties of $\mathrm{C} 45$ steel were determined for specimens with geometrical characteristics defined on the basis of PN-84/H-04334 standard. The performed fatigue tests (5 loading levels, 17 fatigue tests) allowed to determine a stress based fatigue diagram $\left(\mathrm{S}_{\mathrm{a}}-\mathrm{N}\right)$ described by equation:

$$
\log \mathrm{S}_{\mathrm{a}}=-0.1020 \log \mathrm{N}+2,9611
$$

The value of determination coefficient for Wöhler diagram $\left(S_{a}-N\right)$ equals $R^{2}=0,9737$.

The analysis of stress-strain loop recorded during fatigue tests, made it possible to determine the parameter of plastic strain energy $\Delta \mathrm{W}_{\mathrm{pl}}$. The diagram of fatigue life in energy approach $\left(\Delta \mathrm{W}_{\mathrm{pl}}-\mathrm{N}\right)$ was developed on the basis of loops from half of the period of fatigue life $(0.5 \mathrm{~N})$. The equation has the form:

$$
\log \Delta \mathrm{W}_{\mathrm{pl}}=-0.6616 \cdot \log \mathrm{N}+2.9278
$$

The value of determination coefficient for $\Delta \mathrm{W}_{\mathrm{pl}}-\mathrm{N}$ is $\mathrm{R}^{2}=0.9885$.

The diagram of fatigue life in strain approach $\left(\varepsilon_{\mathrm{ac}}-2 \mathrm{~N}_{\mathrm{f}}\right)$ was developed on the basis of loops from half of the period of fatigue life $(0.5 \mathrm{~N})$. The equation has the form:

$$
\varepsilon_{\mathrm{ca}}=0,2179 \cdot\left(2 \mathrm{~N}_{\mathrm{f}}\right)^{-0,4755}+\frac{1204}{215000} \cdot\left(2 \mathrm{~N}_{\mathrm{f}}\right)^{-0,1033}
$$

\subsection{Description of loading programs}

A block of a loading program consists of two sub-blocks of cycles $\left(\mathrm{n}_{\mathrm{o} 1}\right.$ and $\left.\mathrm{n}_{\mathrm{o} 2}\right)$ with amplitudes $\mathrm{S}_{\mathrm{a} 1}$ and $\mathrm{S}_{\mathrm{a} 2}$, where: $\mathrm{S}_{\mathrm{a} 1}=\mathrm{S}_{\mathrm{a} \max }, \mathrm{S}_{\mathrm{a} 2} / \mathrm{S}_{\mathrm{a} 1}=0.75$ and $\mathrm{n}_{\mathrm{o} 1} / \mathrm{n}_{\mathrm{o}}=0.50$ (rys. 2a). Cycles which make up the loadings are characterized by coefficient $R=-1$. The following values of maximum stress values $S_{\text {a max }}: 520 \mathrm{MPa}, 428$ $\mathrm{MPa}$ and $325 \mathrm{MPa}$ were accepted for the tests. For stresses $\mathrm{S}_{\mathrm{a} \max }: 520 \mathrm{MPa}$ the number of cycles in the loading program block was $n_{o}=10$ cycles, whereas for stresses $S_{a \text { max }}: 428 \mathrm{MPa}$ and $325 \mathrm{MPa}$ the number of cycles was $n_{o}=80$. The form of the loading program according to energy based approach is presented in Figure 2b.
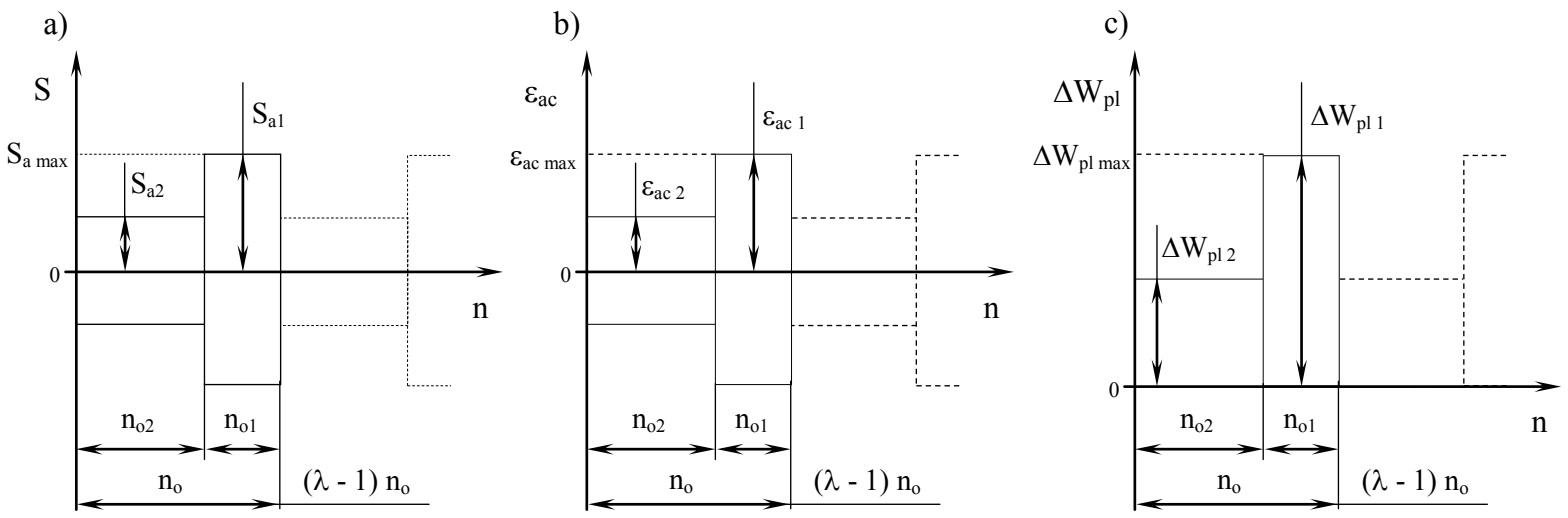

Fig. 1: Scheme of two step loading program in: $a$-stress approach, $b$-strain approach, $c$-energy approach.

The value of plastic strain energy parameter $\Delta \mathrm{W}_{\mathrm{pl}}$ was determined on the basis of equations (1) and (2), with acceptance of a constant value of the number of cycles $\mathrm{N}$ for a given value $\mathrm{S}_{\mathrm{a} i \mathrm{i}}$ and $\Delta \mathrm{W}_{\mathrm{pli}}$. After substitution and transformation, the form of the equation is as follows:

$$
\log \Delta \mathrm{W}_{\mathrm{pl}}=\left(\left(\log \mathrm{S}_{\mathrm{a}}-2,9611\right) \cdot 6,4863\right)+2,9278
$$

The form of the Ramberg-Osgood equation is as follows:

$$
\varepsilon_{\mathrm{ca}}=\frac{\mathrm{S}_{\mathrm{a}}}{215000}+\left(\frac{\mathrm{S}_{\mathrm{a}}}{1233}\right)^{\frac{1}{0,1976}}
$$

The values of energy parameter $\Delta \mathrm{W}_{\mathrm{pl}}$ and strain parameter $\varepsilon_{\mathrm{ac}}$, corresponding to given stresses $\mathrm{S}_{\mathrm{a}}$, are shown in Table 1. 
Tab.1: Parameters of a loading program for stress approach, strain approach and for energy approach.

\begin{tabular}{|c|c|c|c|c|c|c|c|}
\hline \multicolumn{8}{|c|}{ Parameters of loading program } \\
\hline \multicolumn{2}{|c|}{ for stress approach } & \multicolumn{2}{|c|}{ for strain approach } & \multicolumn{2}{|c|}{ for energy approach } & \multirow[b]{2}{*}{$\mathrm{n}_{\mathrm{o}}$} & \multirow[b]{2}{*}{$\mathrm{n}_{\mathrm{o} 1}$} \\
\hline $\mathrm{S}_{\mathrm{a} 1}=\mathrm{S}_{\mathrm{a} \max }$ & $\begin{array}{c}\mathrm{S}_{\mathrm{a} 2}= \\
0.75 \mathrm{~S}_{\mathrm{a} 1}\end{array}$ & $\begin{array}{l}\varepsilon_{\mathrm{ac} 1}= \\
\varepsilon_{\mathrm{ac} \max }\end{array}$ & $\varepsilon_{\mathrm{ac} 2}$ & $\begin{array}{l}\Delta \mathrm{W}_{\mathrm{pl} 1}= \\
\Delta \mathrm{W}_{\mathrm{pl} \max }\end{array}$ & $\Delta \mathrm{W}_{\mathrm{pl} 2}$ & & \\
\hline $\mathrm{MPa}$ & $\mathrm{MPa}$ & $\%$ & $\%$ & $\mathrm{MJ} / \mathrm{m}^{3}$ & $\mathrm{MJ} / \mathrm{m}^{3}$ & cycles & cycle \\
\hline 520.0 & 390.0 & 1.508 & 0.477 & 21.8 & 3.4 & 10 & 5 \\
\hline 428.0 & 321.0 & 0.672 & 0.260 & 6.2 & 0.95 & 80 & 40 \\
\hline 325.0 & 243.8 & 0.268 & 0.141 & 1.03 & 0.16 & 80 & 40 \\
\hline
\end{tabular}

\subsection{Results of fatigue life tests in programmable load conditions}

Experimental fatigue tests in programmable load conditions involved multiple repetition of the loading program, structured as depicted in Figure 1a, until occurrence of the specimen total fracture. The tests were conducted in the conditions of controlled stress $\left(\mathrm{S}_{\mathrm{a} i}=\right.$ const.). The achieved results of fatigue life were approximated with a straight line in order to determine parameters of the equation describing the fatigue life diagram $\left(\mathrm{S}_{\mathrm{a} \text { max }}-\mathrm{N}_{\mathrm{c}}{ }^{\mathrm{Exp}}\right)$

$$
\log S_{a \max }=-0,1281 \cdot \log N_{c}^{\text {Exp }}+3,0837
$$

The value of determination coefficient for diagram $\mathrm{S}_{\mathrm{a} \max }-\mathrm{N}_{\mathrm{c}}{ }^{\mathrm{Exp}}$ is $\mathrm{R}^{2}=0.9855$.

\subsection{Calculations of fatigue life for stress based approach and energy approach}

A linear hypothesis of fatigue life summation was used for fatigue life calculations:

$$
\mathrm{D}=\sum_{\mathrm{i}=1}^{\mathrm{k}} \frac{\mathrm{n}_{\mathrm{oi}}}{\mathrm{N}_{\mathrm{i}}}=1,0
$$

Cyclic properties of $\mathrm{C} 45$ steel in stress approach are described by equation (2), and in energy approach by equation (3). Parameters of loading programs (Fig. 1) are presented in Table1. Results of fatigue calculations are resented in Table 2.

\begin{tabular}{|c|c|c|c|c|c|}
\hline \multicolumn{3}{|c|}{ Parameters of loading program } & \multicolumn{3}{|c|}{ Results of fatigue life for approaches } \\
\hline & & & Stress & Strain & Energy \\
\hline $\mathrm{S}_{\mathrm{a} \max }$ & $\varepsilon_{\mathrm{ac} \max }$ & $\Delta \mathrm{W}_{\mathrm{pl} \mathrm{max}}$ & $\mathrm{N}_{\mathrm{c}}^{\mathrm{Cal}} \mathrm{S}_{\mathrm{S}}$ & $\mathrm{N}_{\mathrm{c}}^{\mathrm{Cal} \_\varepsilon}$ & $\mathrm{N}_{\mathrm{c}}^{\mathrm{Cal} \_\mathrm{E}}$ \\
\hline $\mathrm{MPa}$ & $\%$ & $\mathrm{MJ} / \mathrm{m}^{3}$ & cycles & cycles & cycles \\
\hline 520.0 & 1.508 & 21.8 & 477 & 421 & 476 \\
\hline 428.0 & 0.672 & 6.2 & 3220 & 3667 & 3191 \\
\hline 325.0 & 0.268 & 1.03 & 47855 & 87144 & 48049 \\
\hline
\end{tabular}

Tab. 2: Results of fatigue life calculations in programmable load conditions.

\section{Analysis of tests results}

The obtained fatigue calculation results were analyzed in order to establish consistency of calculation methods with the experimental tests results. The data presented in Figures: 2a, 2b, 2c proves that there is a significant consistency of fatigue calculation results at the level of yield point $\left(\mathrm{S}_{\mathrm{a} \max }=428 \mathrm{MPa}\right)$. 
a)

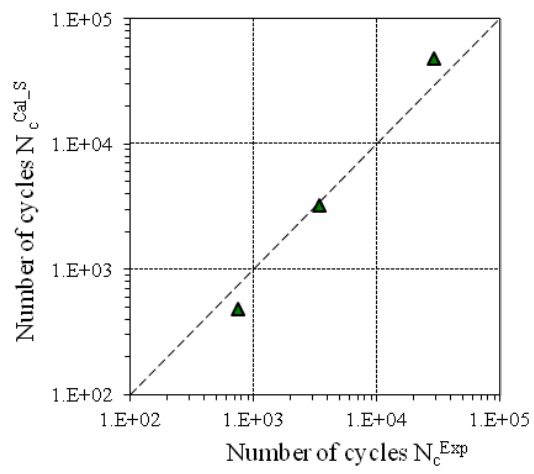

b)

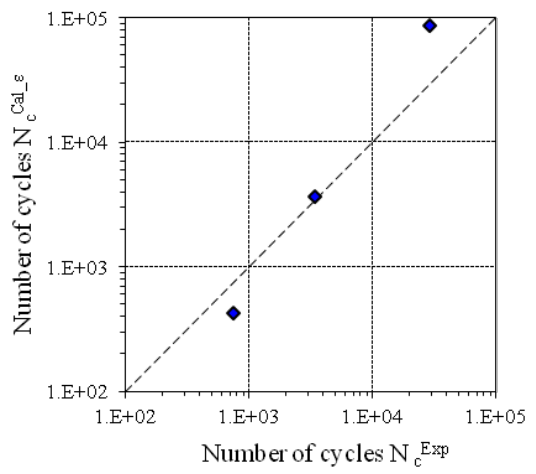

c)

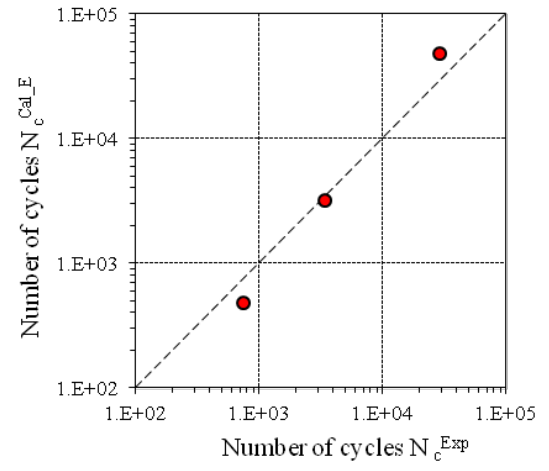

Fig. 2: Comparison of experimental fatigue life $N_{c}^{\text {Exp }}$ with the results of fatigue life calculations in: $a$ - stress approach $N_{c}^{\text {Cal_S }}, b-$ strain approach $N_{c}^{\text {Cal_}} \varepsilon, c-$ energy approach $N_{c}^{\text {Cal_E }}$.

\section{Conclusions}

On the basis of fatigue life tests results performed under the conditions of controlled stress it was found that the value of determination coefficient $\mathrm{R}^{2}$ was higher for fatigue diagrams presented according to energy approach (both for constant amplitude and programmable tests.

A comparative analysis of calculation results with the results of experimental tests for two step loadings revealed a significant influence of the maximal stress values in the spectrum on fatigue life, for each of the applied calculation methods.

\section{References}

Flizikowski, J., Kruszelnicka, W., Michalowski, M., Szala, G., Tomporowski, A., (2017), Bulkhead Door - Critical Evacuation States, Polish Maritime Research, vol. 24, issue: 1, pp. 66-71.

Kurek, M., Lagoda, T., Katzy D., (2014), Comparison of Fatigue Characteristics of some Selected Materials, Materials Testing, vol. 56, pp. 92-95.

Ligaj, B., (2014), Effect of stress ratio on the cumulative value of energy dissipation, Trans Tech Publications, Key Engineering Materials, vol. 598, pp. 125-132, Zurich-Dyrnten, Switzerland.

Soltysiak, R., Boronski, D., (2015), Strain analysis at notch root in laser welded samples using material properties of individual weld zones, International Journal of Fatigue 74, pp. 71-80.

Szala, G., Ligaj, B., (2012), Description of cyclic properties of steel in variability conditions of mean values and amplitudes of loading cycles, Fatigue Failure and Fracture Mechanics, Book series: Materials Science Forum, vol.: 726, pp. 69-76.

Szala, G., Ligaj, B., (2016) Application of hybrid method in calculation of fatigue life for C45 steel (1045 steel) structural components, International Journal of Fatigue 91, pp. 39-49.

Wirwicki, M., Topolinski, T., (2014), Analysis of P-M damage accumulation in zirconium dioxide; testing through gradually increasing load method, 14th Polish Conference on Fracture Mechanics and Fatigue, Location: Cedzyna, POLAND, Date: SEP 23-26, 2013, Key Engineering Materials, vol. 598, pp.255-260.

Zastempowski, M., Bochat, A., Wesołowski, L., (2015), A comparative study of new and traditional designs of hammer mill. Transaction of the ASABE, vol. 58(3), pp.585-596. 